\title{
Study of liquid-liquid equilibria in aqueous two-phase systems formed by poly (ethylene glycol) (PEG) and sodium thiosulfate pentahydrate $\left(\mathrm{Na}_{2} \mathrm{~S}_{2} \mathrm{O}_{3} .5 \mathrm{H}_{2} \mathrm{O}\right)$ at different temperatures
}

\author{
Amanda Cristina de Oliveira a , Filipe Hobi Bordon Sosa a, Mariana Conceição da Costa a \\ Elias de Souza Monteiro Filho ${ }^{\text {b }}$, Roberta Ceriani ${ }^{\text {a, * }}$ \\ ${ }^{a}$ Departamento de Desenvolvimento de Processos e Produtos, Faculdade de Engenharia Química, Universidade Estadual de Campinas (UNICAMP), 13083- \\ 852, Campinas, São Paulo, Brazil \\ ${ }^{\mathrm{b}}$ Departamento de Bioquímica e Tecnologia Química, Instituto de Química, Universidade Estadual Paulista (UNESP), 14800-060, Araraquara, São Paulo, \\ Brazil
}

\section{A R T I C L E I N F O}

\section{Article history:}

Received 27 April 2018

Received in revised form

28 July 2018

Accepted 30 July 2018

Available online 1 August 2018

\section{Keywords:}

Liquid-liquid equilibrium (LLE)

Aqueous two-phase systems (ATPS)

Poly (ethylene glycol) (PEG)

Sodium thiosulfate pentahydrate

\begin{abstract}
A B S T R A C T
This study aimed at providing experimental liquid-liquid equilibrium (LLE) data for aqueous two-phase systems (ATPSs) formed by poly (ethylene glycols) (PEG) of different molecular weights (1500 or 4000 or $6000)$ g.mol ${ }^{-1}$ and sodium thiosulfate pentahydrate at different temperatures (293.15-313.15) K and under atmospheric pressure. Correlations of experimental data of binodal curves were carried out using the Merchuk methodology. The effects of temperature, polymer molecular weight and of the nature of the anion of salts on binodal curves were discussed. In comparison with other anions previously investigated, the salting-out ability of the thiosulfate anion was between those of citrate and tartrate anions. Finally, the Othmer-Tobias and Bancroft equations and the NRTL activity coefficient model were used for correlating tie line compositions.
\end{abstract}

(c) 2018 Elsevier B.V. All rights reserved.

\section{Introduction}

Aqueous two-phase systems (ATPSs) can be obtained through the combination of two water-soluble polymers with different chemical structures $[1,2]$ or a polymer and a salt $[3,4]$ or, according to recent findings, by mixing an ionic liquid and a salt [5,6], wherein the salt used can be either organic or inorganic in both cases.

ATPSs were discovered in 1896, when Beijerinck [7] mixed aqueous solutions of either starches and gelatin or agar-agar and gelatin. Such mixture formed a turbid system that formed two phases spontaneously while resting, in which the upper phase was rich in gelatin and the lower phase in starch or agar-agar [8]. Additional studies were conducted by Ostwald and Hertel in 1929, showing that starches from different sources provided diagrams with different phase compositions and, therefore, variations in molecular interactions influenced compositions of the phases in balance. In the late 40s, Dobry and Boyer-Kawenoki showed separation of phases is also obtained when various types of polymers

\footnotetext{
* Corresponding author.

E-mail address: rceriani@feq.unicamp.br (R. Ceriani).
}

are combined $[9,10]$.

Around the 60s, Albertson [11,12] applied the ATPS formed by poly (ethylene glycol) and dextran in a separation process or biological partition. From this, knowledge of new ATPSs and its application in purification processes have been well explored by researchers. Since studies of Gutowski and his collaborators (2003) [5], ATPSs composed of ionic liquids and salts were also published $[13,14]$, despite their higher costs compared with aqueous systems composed of PEG and Salt [15].

The use of ATPSs in the separation and purification of biomolecules (proteins, enzymes, cells, among others), shows advantages in relation to conventional methods, such as cost reduction, minimization of separation stages and high purification of products. Furthermore, this type of system presents a diversity of application areas, for example, extractive fermentations, determination of solute surface properties, and characterization of ligandnucleic acid binding $[15,16]$. The literature mentions several liquidliquid equilibrium data for (PEG-sodium sulfate) ATPSs [17-22], but no data is available for (PEG + sodium thiosulfate + water) systems. Also, only one set of data for (polyethylene oxide + sodium thiosulfate) ATPS was reported [23]. 
In this study, aqueous two-phase systems composed of PEG $\left(1500,4000\right.$ and $\left.6000 \mathrm{~g} \mathrm{~mol}^{-1}\right)+$ sodium thiosulfate pentahydrate were determined at three different temperatures $T=(293.15$, 303.15 and 313.15$) \mathrm{K}$ with $\mathrm{u}(T)=0.05$ and under atmospheric pressure. The correlations of Othmer-Tobias [24] and Bancroft [25] were used to verify the quality of tie lines obtained from all systems. Quantification of the composition of the tie lines was achieved using the method of Merchuk et al. [26] and following the procedure used by Homrich et al. [27] for calculating standard uncertainties in mass fractions through error propagation. The effects of temperature and polymer molecular weight on the LLE were analyzed.

\section{Experimental}

\subsection{Chemical reagents}

Table 1 lists the compounds used in this study and their characteristics (IUPAC (International Union of Pure and Applied) names, CAS Registry numbers, suppliers and purities in mass fraction). PEGs were standard analytical grade. The number of water molecules of sodium thiosulfate pentahydrate in the aqueous solutions was considered. All chemicals were used as received, without any further purification.http://www.synth.com.br/

\subsection{Experimental procedure}

The phase equilibrium diagrams were obtained by turbidimetry at $T=(293.15,303.15$ and 313.15$) \mathrm{K}$ with $\mathrm{u}(T)=0.05 \mathrm{~K}$, according to the methodology described by Albertsson (1986) [12]. Aqueous solutions of salt at $35 \%(\mathrm{~m} / \mathrm{m})$ and PEG at $50 \%(\mathrm{~m} / \mathrm{m})$ were prepared in equilibrium glass cells connected to a thermostatic bath (Tecnal, model TE-184). The PEG solution was carefully titrated with the salt solution until a cloud point was noted (biphasic region), and the system composition was then registered. After that, a known mass of distilled water was added until the solution turned limpid (single-phase region). Alternating several times between titration with salt solution or distilled water while keeping the system under stirring using a magnetic stirrer (Fisatom, Model 752), identifying the biphasic region was possible. Compositions of ternary systems were determined through mass quantification of all the components, using an analytical balance (Shimadzu. model AX200), accurate to $\pm 0.0001 \mathrm{~g}$.

The tie lines were determined by the gravimetric method, originally proposed by Merchuk et al. [26] through the application of the lever-arm rule for the relation between the mass composition in the upper phase and the system global composition. Ternary mixtures (around $5 \mathrm{~g}$ ) within the two-phase region composed of PEG, salt and water, were prepared in small glass tubes $(9 \mathrm{~mL}$, approx.). Each prepared solution was vigorously stirred for 10 min at $2500 \mathrm{rpm}$ in a vortex (Heldolph, type REAX control). After that, each tube was put into a thermostatic bath at a constant temperature for at least $12 \mathrm{~h}$. Then, both upper and lower phases were carefully separated and weighted. For determination of tie line compositions, a system of four equations (Eqs. (1)-(4)) and four unknowns ( $w_{1}^{I} \cdot w_{2}^{I} . w_{1}^{I I}$ and $\left.w_{2}^{I I}\right)$ were solved. Equations (1) and (2) correspond to experimental binodal curves, and equations (3) and (4) are related to the lever-arm rule [26]:

$$
\begin{aligned}
& w_{1}^{I}=A \cdot \exp \left(B\left(w_{2}^{I}\right)^{0.5}-C\left(w_{2}^{I}\right)^{3}\right) \\
& w_{1}^{I I}=A \cdot \exp \left(B\left(w_{2}^{I I}\right)^{0.5}-C\left(w_{2}^{I I}\right)^{3}\right) \\
& w_{1}^{I}=\frac{w_{1}^{M}}{\alpha}-\left(\frac{1-\alpha}{\alpha}\right) w_{1}^{I I} \\
& w_{2}^{I}=\frac{w_{2}^{M}}{\alpha}-\left(\frac{1-\alpha}{\alpha}\right) w_{2}^{I I}
\end{aligned}
$$

in which $w_{1}$ is the mass fraction of PEG, $w_{2}$ is the mass fraction of salt, superscripts " $I$ ", "II" and $M$ denote, respectively, the upper phase, the lower phase and the initial mixture, $A, B$, and $C$ are regressed parameters from experimental data of the binodal curve, and $\alpha$ is the ratio between the mass in grams of the upper phase and the total mass of the mixture.

The tie-line length, $T L L$, and slope of the tie line, $S$, at different compositions were also calculated using Eqs. (5) and (6), respectively, as follows:

$$
\begin{aligned}
& T L L=\sqrt{\left(w_{1}^{I}-w_{1}^{I I}\right)^{2}+\left(w_{2}^{I}-w_{2}^{I I}\right)^{2}} \\
& S=\frac{w_{1}^{I}-w_{1}^{I I}}{w_{2}^{I}-w_{2}^{I I}}
\end{aligned}
$$

The quality of the LLE data was verified by the semi-empirical equations of Othmer-Tobias [24] (Eq. (7)) and Bancroft [25] (Eq. (8)):

$$
\begin{aligned}
& \frac{1-w_{1}^{I}}{w_{1}^{I}}=k_{1}\left(\frac{1-w_{2}^{I I}}{w_{2}^{I I}}\right)^{n} \\
& \frac{w_{3}^{I I}}{w_{2}^{I I}}=k_{2}\left(\frac{w_{3}^{I}}{w_{1}^{I}}\right)^{r}
\end{aligned}
$$

in which $k_{1}, n, k_{2}$ and $r$ are fitting parameters.

\section{Results and discussion}

\subsection{Binodal curves}

\begin{tabular}{|c|c|c|c|c|}
\hline Compounds & IUPAC NAME & CAS Registry No. & Supplier & $\begin{array}{l}\text { Purity } \\
\text { (mass fraction) }\end{array}$ \\
\hline PEG 1500 & Poly (ethylene glycol) 1500 & $25322-68-3$ & Synth & - \\
\hline PEG 4000 & Poly (ethylene glycol) 4000 & $25322-68-3$ & Synth & - \\
\hline PEG 6000 & Poly (ethylene glycol) 6000 & $25322-68-3$ & Synth & - \\
\hline Sodium thiosulfate Pentahydrate & Sodium sulfurothioate Hydrate & $10102-17-7$ & Synth & 0.995 \\
\hline
\end{tabular}

Experimental data from binodal curves obtained at temperatures of $T=(293.15-313.15) \mathrm{K}$ with $\mathrm{u}(T)=0.05 \mathrm{~K}$ under atmospheric pressure for all systems formed through the combination of the three PEGs (1500, 4000 or 6000 ) with sodium thiosulfate pentahydrate are given in Table 2 and represented graphically in Fig. 1.

Table 1

Source and purity of the chemicals used in this study. 
Table 2

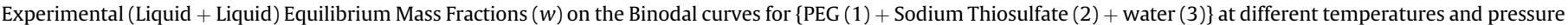
$p=0.094 \mathrm{MPa}^{\mathrm{a}}$.

\begin{tabular}{|c|c|c|c|c|c|c|c|c|c|c|c|}
\hline \multicolumn{4}{|c|}{$293.15 \mathrm{~K}$} & \multicolumn{4}{|c|}{$303.15 \mathrm{~K}$} & \multicolumn{4}{|c|}{$313.15 \mathrm{~K}$} \\
\hline $100 w_{1}$ & $100 w_{2}$ & $100 w_{1}$ & $100 w_{2}$ & $100 w_{1}$ & $100 w_{2}$ & $100 w_{1}$ & $100 w_{2}$ & $100 w_{1}$ & $100 w_{2}$ & $100 w_{1}$ & $100 w_{2}$ \\
\hline \multicolumn{12}{|c|}{ PEG 1500} \\
\hline 39.06 & 4.36 & 18.57 & 10.57 & 40.94 & 3.95 & 10.77 & 13.78 & 42.15 & 3.52 & 18.84 & 9.84 \\
\hline 38.08 & 4.57 & 17.84 & 10.90 & 39.36 & 4.19 & 9.93 & 14.17 & 40.41 & 3.77 & 18.30 & 10.05 \\
\hline 37.10 & 4.78 & 17.11 & 11.23 & 37.78 & 4.44 & 9.16 & 14.53 & 38.98 & 3.98 & 17.76 & 10.26 \\
\hline 36.17 & 4.98 & 16.42 & 11.55 & 35.64 & 4.85 & 8.51 & 14.84 & 37.91 & 4.22 & 16.78 & 10.64 \\
\hline 35.25 & 5.18 & 15.73 & 11.88 & 34.00 & 5.28 & 7.89 & 15.16 & 36.85 & 4.45 & 15.88 & 11.00 \\
\hline 34.64 & 5.29 & 15.08 & 12.17 & 32.35 & 5.70 & 7.53 & 15.36 & 35.82 & 4.70 & 15.03 & 11.35 \\
\hline 33.66 & 5.53 & 14.43 & 12.48 & 31.01 & 6.17 & 7.22 & 15.51 & 34.79 & 4.94 & 14.27 & 11.66 \\
\hline 32.94 & 5.68 & 13.27 & 13.04 & 28.94 & 6.77 & 6.96 & 15.63 & 33.61 & 5.26 & 13.36 & 12.02 \\
\hline 31.78 & 6.01 & 12.28 & 13.52 & 26.86 & 7.37 & 6.67 & 15.79 & 32.43 & 5.58 & 12.51 & 12.37 \\
\hline 30.59 & 6.29 & 11.30 & 14.01 & 25.22 & 7.83 & 6.39 & 15.95 & 31.39 & 5.87 & 11.95 & 12.69 \\
\hline 30.14 & 6.44 & 10.53 & 14.39 & 24.21 & 8.20 & 6.13 & 16.11 & 30.25 & 6.17 & 11.39 & 13.01 \\
\hline 29.18 & 6.72 & 9.85 & 14.72 & 23.20 & 8.56 & 5.90 & 16.24 & 29.03 & 6.50 & 10.54 & 13.37 \\
\hline 28.22 & 6.99 & 9.05 & 15.18 & 21.96 & 9.04 & 5.68 & 16.37 & 27.80 & 6.83 & 9.69 & 13.72 \\
\hline 28.17 & 7.02 & 8.60 & 15.41 & 20.71 & 9.52 & 5.45 & 16.51 & 26.90 & 7.12 & 8.90 & 14.07 \\
\hline 28.12 & 7.05 & 8.40 & 15.51 & 19.96 & 9.77 & 5.29 & 16.62 & 25.93 & 7.40 & 8.12 & 14.42 \\
\hline 27.16 & 7.35 & 7.77 & 15.85 & 18.92 & 10.21 & 5.29 & 16.62 & 25.15 & 7.64 & 7.68 & 14.63 \\
\hline 26.20 & 7.65 & 7.14 & 16.20 & 17.88 & 10.64 & 4.84 & 16.99 & 24.34 & 7.89 & 7.24 & 14.84 \\
\hline 25.06 & 8.05 & & & 16.58 & 11.26 & 4.42 & 17.27 & 23.61 & 8.09 & 6.76 & 15.09 \\
\hline 23.92 & 8.44 & & & 16.26 & 11.33 & 4.01 & 17.59 & 22.89 & 8.36 & 6.28 & 15.35 \\
\hline 22.81 & 8.86 & & & 15.20 & 11.87 & 3.55 & 17.86 & 22.14 & 8.58 & 5.72 & 15.72 \\
\hline 21.69 & 9.28 & & & 14.49 & 12.11 & 3.10 & 18.13 & 21.41 & 8.87 & 5.15 & 16.09 \\
\hline 20.90 & 9.60 & & & 13.75 & 12.44 & 2.57 & 18.53 & 20.74 & 9.11 & 4.67 & 16.44 \\
\hline 20.11 & 9.92 & & & 13.02 & 12.77 & 2.04 & 18.92 & 20.10 & 9.35 & 4.20 & 16.78 \\
\hline 19.34 & 10.24 & & & 11.79 & 13.32 & & & 19.47 & 9.59 & & \\
\hline \multicolumn{12}{|c|}{ PEG 4000} \\
\hline 41.85 & 3.21 & 9.88 & 11.38 & 46.04 & 1.69 & 9.19 & 11.02 & 43.41 & 2.99 & 17.25 & 7.60 \\
\hline 40.53 & 3.36 & 9.24 & 11.67 & 45.50 & 1.87 & 8.65 & 11.26 & 42.07 & 3.12 & 16.14 & 7.93 \\
\hline 39.20 & 3.50 & 8.68 & 11.92 & 44.37 & 2.10 & 8.17 & 11.47 & 40.35 & 3.35 & 15.12 & 8.24 \\
\hline 38.02 & 3.67 & 8.19 & 12.12 & 43.24 & 2.33 & 7.80 & 11.61 & 39.27 & 3.45 & 14.25 & 8.51 \\
\hline 36.70 & 3.89 & 7.80 & 12.31 & 41.94 & 2.59 & 7.44 & 11.75 & 40.74 & 3.24 & 13.31 & 8.80 \\
\hline 35.17 & 4.08 & 7.78 & 12.30 & 40.65 & 2.84 & 7.10 & 11.88 & 38.19 & 3.55 & 12.48 & 9.08 \\
\hline 33.88 & 4.38 & 7.76 & 12.29 & 39.01 & 3.11 & 6.77 & 12.01 & 37.01 & 3.70 & 11.77 & 9.29 \\
\hline 32.17 & 4.71 & 7.28 & 12.53 & 37.38 & 3.38 & 6.48 & 12.14 & 38.31 & 3.54 & 10.90 & 9.56 \\
\hline 30.98 & 4.92 & 6.80 & 12.77 & 36.11 & 3.61 & 5.81 & 12.40 & 38.44 & 3.53 & 10.19 & 9.80 \\
\hline 29.65 & 5.18 & 6.32 & 13.00 & 34.85 & 3.85 & 5.66 & 12.61 & 38.68 & 3.50 & 9.11 & 10.20 \\
\hline 28.34 & 5.49 & 5.85 & 13.25 & 34.04 & 4.08 & 5.45 & 12.61 & 32.06 & 4.26 & 8.28 & 10.50 \\
\hline 26.99 & 5.84 & 5.23 & 13.60 & 33.23 & 4.31 & 5.26 & 12.69 & 33.94 & 4.06 & 7.60 & 10.75 \\
\hline 25.96 & 6.03 & 4.75 & 13.83 & 32.17 & 4.54 & 5.10 & 12.83 & 35.82 & 3.85 & 7.02 & 10.97 \\
\hline 27.07 & 5.81 & 4.34 & 14.06 & 31.10 & 4.76 & 4.96 & 12.84 & 34.86 & 3.94 & 6.53 & 11.17 \\
\hline 25.03 & 6.31 & 3.99 & 14.28 & 29.84 & 5.01 & 4.76 & 12.93 & 33.89 & 4.03 & 6.10 & 11.33 \\
\hline 24.16 & 6.54 & 3.65 & 14.51 & 28.57 & 5.25 & 4.60 & 13.00 & 32.97 & 4.15 & 5.66 & 11.49 \\
\hline 23.28 & 6.77 & 3.37 & 14.70 & 26.50 & 5.60 & 4.44 & 13.07 & 32.06 & 4.26 & 5.25 & 11.67 \\
\hline 22.43 & 7.01 & 2.71 & 15.09 & 24.54 & 6.03 & 4.19 & 13.22 & 31.04 & 4.46 & 5.26 & 11.70 \\
\hline 21.57 & 7.24 & 2.16 & 15.41 & 22.60 & 6.57 & 3.94 & 13.38 & 30.02 & 4.66 & 5.06 & 11.76 \\
\hline 20.22 & 7.63 & 1.72 & 15.87 & 21.03 & 6.98 & 3.94 & 13.38 & 29.15 & 4.85 & 4.77 & 11.87 \\
\hline 18.94 & 8.00 & & & 19.62 & 7.35 & 3.25 & 13.63 & 28.28 & 5.05 & 4.47 & 12.00 \\
\hline 17.72 & 8.42 & & & 18.09 & 7.82 & 2.77 & 13.86 & 27.49 & 5.21 & 4.14 & 12.15 \\
\hline 16.59 & 8.80 & & & 16.72 & 8.25 & 2.29 & 14.07 & 26.70 & 5.38 & 3.58 & 12.49 \\
\hline 15.41 & 9.23 & & & 15.23 & 8.77 & 2.00 & 14.28 & 25.35 & 5.70 & 3.02 & 12.82 \\
\hline 14.51 & 9.56 & & & 13.98 & 9.21 & 1.72 & 14.53 & 24.22 & 5.93 & 2.50 & 13.19 \\
\hline 13.71 & 9.85 & & & 12.87 & 9.62 & 1.45 & 14.83 & 23.14 & 6.12 & 2.09 & 13.51 \\
\hline 12.74 & 10.24 & & & 11.92 & 9.98 & & & 22.12 & 6.33 & 1.77 & 13.86 \\
\hline 11.98 & 10.52 & & & 11.13 & 10.27 & & & 21.08 & 6.60 & 1.49 & 14.12 \\
\hline 11.27 & 10.82 & & & 10.37 & 10.56 & & & 19.85 & 6.87 & 1.29 & 14.39 \\
\hline 10.61 & 11.10 & & & 9.74 & 10.80 & & & 18.53 & 7.22 & & \\
\hline \multicolumn{12}{|c|}{ PEG 6000} \\
\hline 43.31 & 2.80 & 12.08 & 9.80 & 45.00 & 2.24 & 14.54 & 8.40 & 44.13 & 2.61 & 14.54 & 7.70 \\
\hline 41.93 & 2.97 & 11.31 & 10.08 & 43.68 & 2.45 & 13.87 & 8.62 & 42.85 & 2.68 & 13.88 & 7.90 \\
\hline
\end{tabular}

a Standard uncertainties $\mathrm{u}$ are $\mathrm{u}(\mathrm{T})=0.05 \mathrm{~K}, \mathrm{u}(\mathrm{w})=0.0001$, and $\mathrm{u}(\mathrm{P})=0.5 \mathrm{kPa}$. 


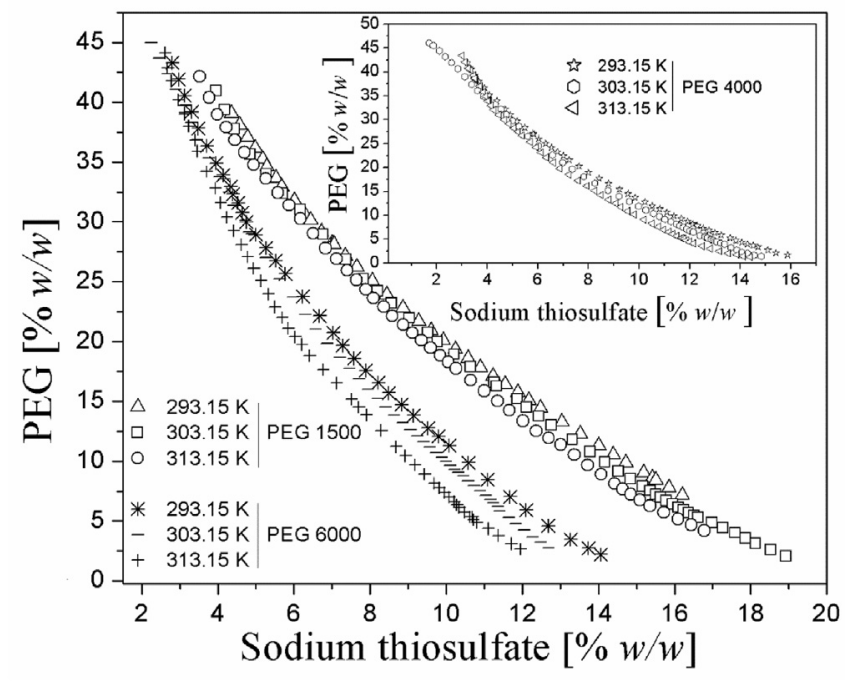

Fig. 1. Effect of temperature and type of PEG on binodal curves for the systems composed of PEG (1) + Sodium Thiosulfate (2) + water (3) ATPSs under atmospheric pressure.

The literature reports that increasing temperature, biphasic region in some ATPSs of the type PEG-salt is extended [28,29]. This relationship between temperature and two-phase region size is associated with the endothermic nature of the phase-separation process. In Fig. 1, an increase in temperature induces a subtle variation in solubility curves (or an increase in the size of the twophase region), which is not statistically significant [30]. However, at higher polymer concentrations, this effect is not well defined, corroborating with Zafarani-Moattar and coworkers [31,32], who observed that, in some ATPSs formed by PEG-salt, temperature effect is undefined and, sometimes, inverted in regions where binodal curves are richer in PEG. In these regions, the intensity of the interactions between PEG molecules is responsible for phase separation, and the expectation is that decreasing temperature will cause the formation of two-phases due to an increased repulsion between PEG molecules [32]. According to Zafarani-Moattar and Sadeghi (2001) [32], in salt-rich regions, the behavior of the binodal curves under a variation in temperature depends mainly on the kind of the salt used. The behavior of these systems in this other region may be due to the different solvation properties of the salt

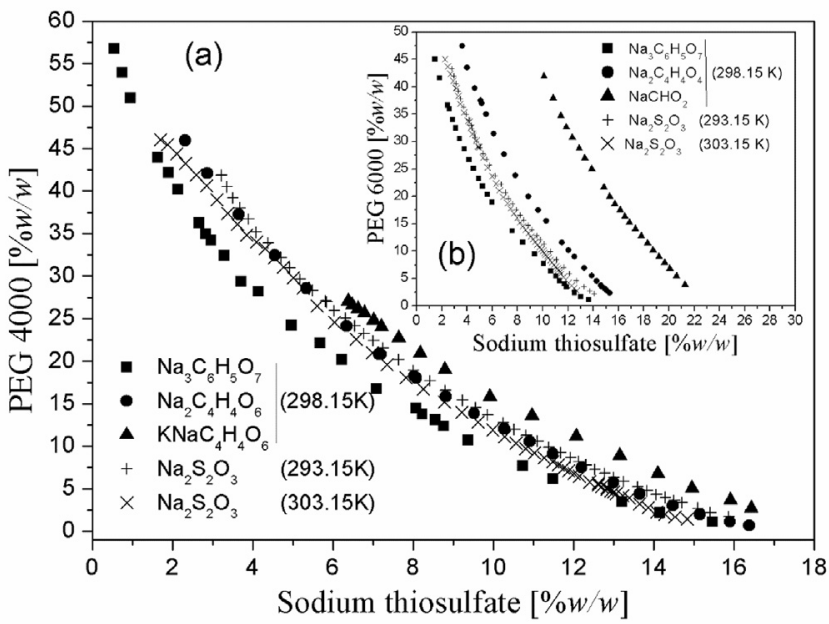

Fig. 2. Effect of salt anions on binodal curves for the systems composed of PEG 4000 (or PEG 6000) (1) + Salt (2) + water (3) ATPSs under atmospheric pressure: (a) salts: sodium citrate $\left(\mathrm{Na}_{3} \mathrm{C}_{6} \mathrm{H}_{5} \mathrm{O}_{7}\right)$, sodium tartrate $\left(\mathrm{Na}_{2} \mathrm{C}_{4} \mathrm{H}_{4} \mathrm{O}_{6}\right)$, sodium potassium tartrate $\left(\mathrm{KNaC}_{4} \mathrm{H}_{4} \mathrm{O}_{6}\right)$, sodium thiosulfate $\left(\mathrm{Na}_{2} \mathrm{~S}_{2} \mathrm{O}_{3}\right)$ (this study); (b) salts: sodium citrate $\left(\mathrm{Na}_{3} \mathrm{C}_{6} \mathrm{H}_{5} \mathrm{O}_{7}\right)$, sodium succinate $\left(\mathrm{Na}_{2} \mathrm{C}_{4} \mathrm{H}_{4} \mathrm{O}_{4}\right)$, sodium formate $\left(\mathrm{NaCHO}_{2}\right)$, sodium thiosulfate $\left(\mathrm{Na}_{3} \mathrm{C}_{6} \mathrm{H}_{5} \mathrm{O}_{7}\right)$ (this study).

\section{ions at different temperatures.}

The effect of PEG molecular weight in the size of the biphasic region was as expected [11,12]. An increase in molecular weight of PEG promotes an increase in the biphasic region due to a reduction of the solubility of PEG in water [33], being less pronounced or even inverted between PEGs 4000 and 6000, in PEG-rich regions, consorting with results of Zhang et al. [34] for PEGs 1000 e 2000. This behavior has already been shown in the literature [35] and may be attributed to the incompatibility between the system components, due to an increase in the hydrophobicity of PEGs of higher molecular weights. In this way, the phase splitting is achieved at lower concentrations of PEGs of higher molecular weights, which tends to lower its water absorption capacity. The effect of PEG molecular weight in binodal curves is depicted in Fig. 1 and in Figure S4 in the Supplementary Material. As noted, systems formed by PEGs of higher molecular weight have greater ability to form two-phases, which suggests that they may be somewhat better for separation of biomolecules [36].

In order to correlate LLE data in terms of mass fractions, the

Table 3

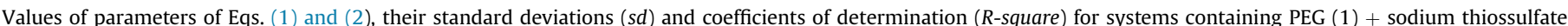
(2) + water (3) at different temperatures.

\begin{tabular}{|c|c|c|c|c|c|}
\hline $\mathrm{T} / \mathrm{K}$ & A $(95 \% \text { C.B. })^{b}$ & B $(95 \% \text { C.B. })^{b}$ & C $(95 \% \text { C.B. })^{b}$ & $\mathrm{R}^{2}$ & $\mathrm{sd}^{\mathrm{a}}$ \\
\hline \multicolumn{6}{|c|}{ PEG 1500} \\
\hline 293.15 & $1.0786(1.0445 .1 .1126)$ & $-4.8246(-4.9604,-4.6887)$ & $167.4698(158.5552,176.3843)$ & 0.9996 & 0.0019 \\
\hline 303.15 & $0.9325(0.8852,0.9799)$ & $-4.1830(-4.4026,-3.9634)$ & $245.7538(232.7616,258.7460)$ & 0.9989 & 0.0038 \\
\hline 313.15 & $0.9595(0.9351,0.9840)$ & $-4.4024(-4.5175,-4.2872)$ & $264.1662(254.8999,273.4324)$ & 0.9996 & 0.0021 \\
\hline \multicolumn{6}{|c|}{ PEG 4000} \\
\hline 293.15 & $1.1407(1.0937,1.1878)$ & $-5.6245(-5.8243,-5.4248)$ & $393.6823(372.8304,414.5341)$ & 0.9993 & 0.0031 \\
\hline 303.15 & $0.8233(0.7951,0.8517)$ & $-4.2188(-4.4120,-4.0256)$ & $623.3137(593.8675,652,7599)$ & 0.9988 & 0.0049 \\
\hline 313.15 & $1.3505(1.2661,1.4350)$ & $-6.5819(-6.9075,-6.2562)$ & $603.2373(555.3699,651,1046)$ & 0.9988 & 0.0048 \\
\hline \multicolumn{6}{|c|}{ PEG 6000} \\
\hline 293.15 & $1.1370(1.0780,1.1952)$ & $-5.7664(-6.0318,-5.5009)$ & $514.4199(473.3316,555.5082)$ & 0.9991 & 0.0037 \\
\hline 303.15 & $1.0219(0.9805,1.0633)$ & $-5.3086(-5.5282,-5.0890)$ & $692.4398(655.5115,729,3680)$ & 0.9990 & 0.0040 \\
\hline 313.15 & $1.3902(1.3254,1.4549)$ & $-7.0865(-7.3414,-6.8316)$ & $736.0536(687.0734,785,0338)$ & 0.9992 & 0.0037 \\
\hline
\end{tabular}


Table 4

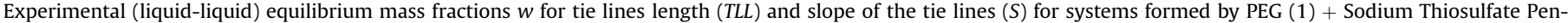
tahydrate (2) + water (3) at different temperatures and Pressure $p=0.094 \mathrm{MPa}^{\mathrm{a}}$.

\begin{tabular}{|c|c|c|c|c|c|c|c|c|c|c|c|c|}
\hline \multirow[t]{2}{*}{$T L$} & \multicolumn{2}{|c|}{ Global composition } & \multicolumn{4}{|c|}{ Top phase: PEG-rich phase } & \multicolumn{4}{|c|}{ Bottom phase: salt-rich phase } & \multirow[t]{2}{*}{$T L L$} & \multirow[t]{2}{*}{$S$} \\
\hline & $100 w_{1}$ & $100 w_{2}$ & $100 w_{1}$ & $u\left(w_{1}\right)$ & $100 w_{2}$ & $u\left(w_{2}\right)$ & $100 w_{1}$ & $u\left(w_{1}\right)$ & $100 w_{2}$ & $u\left(w_{2}\right)$ & & \\
\hline \multicolumn{13}{|c|}{ PEG 1500} \\
\hline \multicolumn{13}{|c|}{$T=293.15 \mathrm{~K}$} \\
\hline 1 & 17.96 & 12.08 & 27.70 & 0.17 & 7.22 & 0.42 & 4.25 & 0.20 & 18.92 & 0.48 & 26.20 & -2.00 \\
\hline 2 & 18.01 & 13.38 & 32.38 & 0.11 & 5.87 & 0.37 & 2.05 & 0.12 & 21.72 & 0.41 & 34.22 & -1.91 \\
\hline 3 & 17.99 & 14.65 & 37.65 & 0.06 & 4.61 & 0.30 & 1.32 & 0.05 & 23.16 & 0.26 & 40.80 & -1.96 \\
\hline 4 & 17.97 & 15.95 & 42.46 & 0.03 & 3.67 & 0.24 & 0.83 & 0.02 & 24.55 & 0.17 & 46.57 & -1.99 \\
\hline \multicolumn{13}{|c|}{$T=303.15 \mathrm{~K}$} \\
\hline 1 & 17.97 & 12.07 & 31.07 & 0.50 & 6.19 & 0.89 & 2.96 & 0.58 & 18.82 & 0.94 & 30.82 & -2.23 \\
\hline 2 & 18.04 & 13.42 & 36.43 & 0.18 & 4.77 & 0.63 & 1.25 & 0.16 & 21.32 & 0.58 & 38.88 & -2.13 \\
\hline 3 & 18.02 & 14.68 & 40.05 & 0.08 & 3.94 & 0.53 & 0.58 & 0.06 & 23.18 & 0.42 & 43.90 & -2.05 \\
\hline 4 & 18.00 & 15.91 & 44.47 & 0.04 & 3.07 & 0.46 & 0.32 & 0.03 & 24.49 & 0.31 & 49.07 & -2.06 \\
\hline \multicolumn{13}{|c|}{$T=313.15 \mathrm{~K}$} \\
\hline 1 & 17.98 & 12.78 & 37.43 & 0.08 & 4.36 & 0.31 & 1.74 & 0.10 & 19.80 & 0.37 & 38.89 & -2.31 \\
\hline 2 & 17.51 & 14.27 & 42.11 & 0.05 & 3.41 & 0.28 & 0.86 & 0.06 & 21.61 & 0.31 & 45.09 & -2.27 \\
\hline 3 & 18.02 & 15.26 & 45.26 & 0.03 & 2.86 & 0.24 & 0.41 & 0.02 & 23.27 & 0.21 & 49.28 & -2.20 \\
\hline 4 & 17.94 & 16.53 & 48.48 & 0.01 & 2.38 & 0.21 & 0.20 & 0.01 & 24.74 & 0.15 & 53.21 & -2.16 \\
\hline \multicolumn{13}{|c|}{$\begin{array}{l}\text { PEG 4000 } \\
T=293.15 \mathrm{~K}\end{array}$} \\
\hline 1 & 18.00 & 9.50 & 25.17 & 0.12 & 6.31 & 0.38 & 1.82 & 0.27 & 16.72 & 0.86 & 25.56 & -2.24 \\
\hline 2 & 17.99 & 10.91 & 30.76 & 0.05 & 5.02 & 0.32 & 0.70 & 0.07 & 18.89 & 0.44 & 33.10 & -2.17 \\
\hline 3 & 17.95 & 11.53 & 33.79 & 0.03 & 4.42 & 0.28 & 0.54 & 0.03 & 19.41 & 0.28 & 36.47 & -2.22 \\
\hline 4 & 17.97 & 14.04 & 40.44 & 0.01 & 3.31 & 0.23 & 0.09 & 0.01 & 22.58 & 0.19 & 44.72 & -2.09 \\
\hline \multicolumn{13}{|c|}{$\mathrm{T}=303.15 \mathrm{~K}$} \\
\hline 1 & 18.07 & 10.25 & 31.35 & 0.05 & 4.60 & 0.33 & 0.43 & 0.07 & 17.75 & 0.44 & 33.61 & -2.35 \\
\hline 2 & 18.06 & 11.50 & 35.84 & 0.02 & 3.62 & 0.30 & 0.13 & 0.02 & 19.45 & 0.30 & 39.06 & -2.25 \\
\hline 3 & 17.95 & 12.73 & 39.41 & 0.01 & 2.92 & 0.27 & 0.04 & 0.01 & 20.91 & 0.23 & 43.29 & -2.19 \\
\hline 4 & 18.02 & 14.03 & 42.18 & 0.00 & 2.45 & 0.25 & 0.01 & 0.00 & 22.67 & 0.18 & 46.77 & -2.09 \\
\hline \multicolumn{13}{|c|}{$T=313.15 \mathrm{~K}$} \\
\hline 1 & 18.01 & 12.78 & 37.43 & 0.06 & 4.36 & 0.40 & 1.74 & 0.07 & 19.80 & 0.45 & 38.89 & -2.31 \\
\hline 2 & 18.00 & 14.27 & 42.11 & 0.02 & 3.41 & 0.34 & 0.86 & 0.02 & 21.61 & 0.30 & 45.09 & -2.27 \\
\hline 3 & 18.00 & 15.26 & 45.26 & 0.01 & 2.86 & 0.30 & 0.41 & 0.01 & 23.27 & 0.23 & 49.28 & -2.20 \\
\hline 4 & 18.04 & 16.53 & 48.48 & 0.00 & 2.38 & 0.28 & 0.20 & 0.00 & 24.74 & 0.19 & 53.21 & -2.16 \\
\hline \multicolumn{13}{|c|}{$\begin{array}{l}\text { PEG } 6000 \\
T=293.15 \mathrm{~K}\end{array}$} \\
\hline 1 & 18.01 & 8.93 & 25.56 & 0.14 & 5.82 & 0.44 & 1.57 & 0.31 & 15.71 & 0.96 & 25.95 & -2.43 \\
\hline 2 & 18.00 & 10.19 & 31.57 & 0.07 & 4.57 & 0.38 & 0.70 & 0.09 & 17.36 & 0.49 & 33.42 & -2.41 \\
\hline 3 & 18.01 & 11.48 & 36.24 & 0.03 & 3.75 & 0.33 & 0.27 & 0.03 & 19.01 & 0.33 & 39.07 & -2.36 \\
\hline 4 & 17.63 & 12.48 & 38.86 & 0.01 & 3.34 & 0.31 & 0.14 & 0.01 & 20.02 & 0.26 & 42.15 & -2.32 \\
\hline \multicolumn{13}{|c|}{$T=303.15 \mathrm{~K}$} \\
\hline 1 & 18.09 & 10.15 & 33.80 & 0.04 & 4.00 & 0.30 & 0.36 & 0.05 & 17.09 & 0.34 & 35.91 & -2.56 \\
\hline 2 & 18.07 & 11.51 & 37.18 & 0.01 & 3.43 & 0.27 & 0.08 & 0.01 & 19.12 & 0.26 & 40.28 & -2.36 \\
\hline 3 & 18.06 & 12.76 & 41.04 & 0.00 & 2.85 & 0.25 & 0.02 & 0.00 & 20.54 & 0.20 & 44.67 & -2.32 \\
\hline 4 & 17.96 & 14.00 & 40.50 & 0.00 & 4.00 & 0.28 & 0.00 & 0.00 & 22.83 & 0.22 & 44.66 & -2.15 \\
\hline \multicolumn{13}{|c|}{$T=313.15 \mathrm{~K}$} \\
\hline 1 & 18.04 & 10.18 & 33.58 & 0.03 & 4.19 & 0.27 & 0.48 & 0.04 & 16.93 & 0.30 & 35.47 & -2.60 \\
\hline 2 & 18.05 & 11.45 & 38.25 & 0.01 & 3.52 & 0.23 & 0.18 & 0.01 & 18.42 & 0.19 & 40.88 & -2.56 \\
\hline 3 & 17.99 & 12.39 & 41.39 & 0.00 & 3.13 & 0.19 & 0.09 & 0.00 & 19.49 & 0.13 & 44.42 & -2.52 \\
\hline 4 & 18.05 & 13.37 & 43.56 & 0.00 & 2.88 & 0.17 & 0.03 & 0.00 & 20.77 & 0.10 & 47.07 & -2.43 \\
\hline
\end{tabular}

a Standard uncertainties are $u(T)=0.05 \mathrm{~K} . u(p)=10 \mathrm{kPa} u\left(w_{i}\right)<0.9$. for $i=1$ or 2 in total composition.

values of parameters of Eqs. (1) and (2) were obtained through a nonlinear regression (least-square method) using data of Table 2. Table 3 shows regressed values for all systems, coefficients of determination, R-square (higher than 0.99), and standard deviations, $s d$ (lower than 0.0049 ), indicating a good representation of data.

Salting-out ability can be related to the Gibbs energy of hydration of ions $\left(\Delta G_{h y d}\right)$ [37]. Thus, we compared the salting-out ability of anion, studied in the ATPSs of this study, with other anions of sodium salts analyzing the phase diagrams together with $\left(\Delta G_{\text {hyd }}\right)$ values. So, ATPSs involving PEG 4000 (or PEG 6000) and these salts at $298.15 \mathrm{~K}$ were found in the literature [37-41] and compared with systems obtained in this study at 293.15 and $303.15 \mathrm{~K}$, even though our data were obtained at different temperatures. Firstly, the estimated values of $\left(\Delta G_{h y d}\right)$ calculated with the procedure described by Marcus [42], and reported in the literature [39,43,44], were considered in this analysis. Fig. 2 shows clearly that for salts that share a common cation but contain different anions, salting-out 


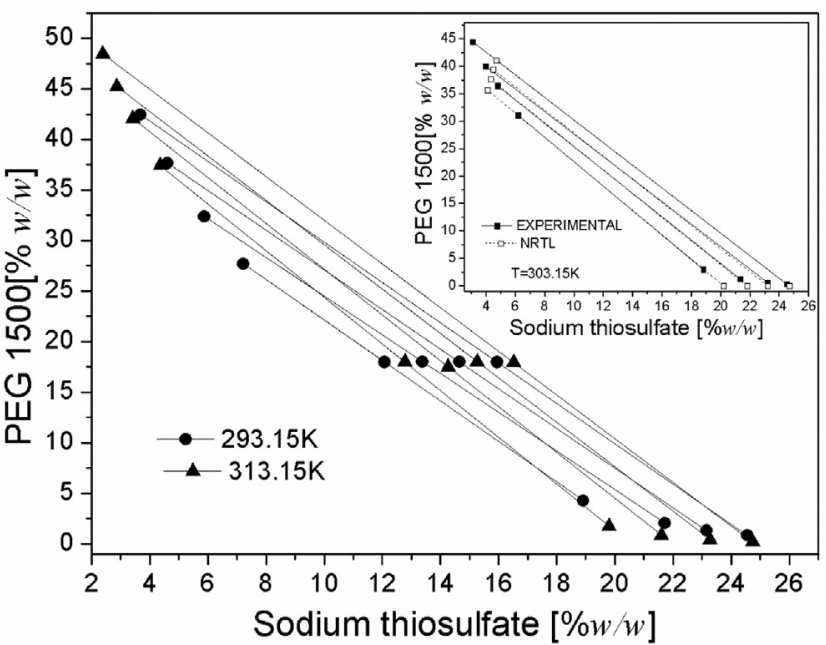

Fig. 3. Liquid-liquid equilibria at different temperatures for the systems composed of PEG 1500 (1) + Sodium Thiosulfate (2) + water (3) ATPSs under atmospheric pressure.

ability of anions follows the sequence (numbers in parentheses are the Gibbs energy of hydration of ions): $\mathrm{C}_{6} \mathrm{H}_{5} \mathrm{O}_{7}^{-3}\left(-2793 \mathrm{~kJ} \mathrm{~mol}^{-1}\right)$ $[43]>S_{2} \mathrm{O}_{3}^{-2}\left(-1160 \mathrm{~kJ} \mathrm{~mol}^{-1}\right)[44]>\mathrm{C}_{4} \mathrm{H}_{4} \mathrm{O}_{6}^{-2}\left(-1010 \mathrm{~kJ} \mathrm{~mol}^{-1}\right)[44]$ $>\mathrm{CHO}^{-2}\left(-395 \mathrm{~kJ} \mathrm{~mol}^{-1}\right)$ [39]. Secondly, in order to evaluate the effectiveness in the phases formation of sodium potassium tartrate and include it in the above sequence, analyzing the $\left(\Delta G_{h y d}\right)$ of the cations $\mathrm{K}^{+}$and $\mathrm{Na}^{+}$was necessary. Marcus et al. [42] also reported experimental values of $\left(\Delta G_{h y d}\right)$ for cations $\mathrm{K}^{+}$and $\mathrm{Na}^{+}$ as $-295 \mathrm{~kJ} \mathrm{~mol}^{-1}$ and $-365 \mathrm{~kJ} \mathrm{~mol}^{-1}$, respectively. Considering that the negative value of the $\left(\Delta G_{h y d}\right)$ of $\mathrm{K}^{+}$is lower than that of $\mathrm{Na}^{+}$, the expectation is that the salting out ability of the di-sodium tartrate salt would be higher than that of sodium potassium tartrate. Therefore, the final sequence for the salting-out ability of the anion in Fig. 2(a) and (b) is: $\mathrm{C}_{6} \mathrm{H}_{5} \mathrm{O}_{7}^{-3}$ (citrate) $>\mathrm{S}_{2} \mathrm{O}_{3}^{-2}$ (thiosulfate) $>\mathrm{C}_{4} \mathrm{H}_{4} \mathrm{O}_{6}^{-2}$ (tartrate) $>\mathrm{KC}_{4} \mathrm{H}_{4} \mathrm{O}_{6}^{-2}$ (Ktartrate) $>\mathrm{C}_{4} \mathrm{H}_{4} \mathrm{O}_{4}^{-2}$ (succinate) $>\mathrm{CHO}^{-2}$ (formate). In this way, the best salting-out effect in Fig. 2(a) and (b) is observed for ATPSs with sodium citrate that presented a more negative $\left(\Delta G_{h y d}\right)$ value. These results are in accordance with those from Li et al. [45], which showed that the salting-out effect of citrate, tartrate and succinate ions follows the

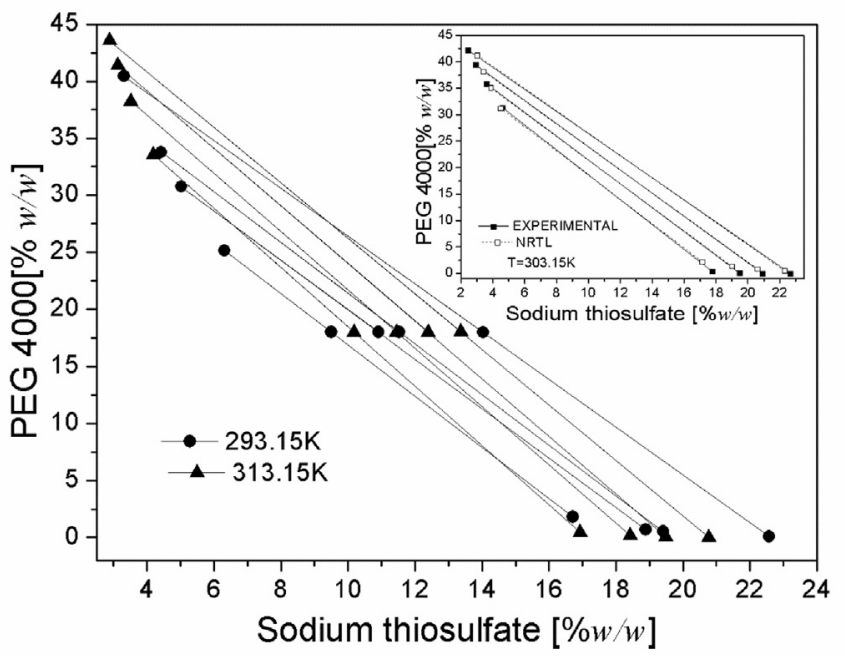

Fig. 4. Liquid-liquid equilibria at different temperatures for the systems composed of PEG 4000 + Sodium Thiosulfate (2) + water (3) ATPSs under atmospheric pressure.

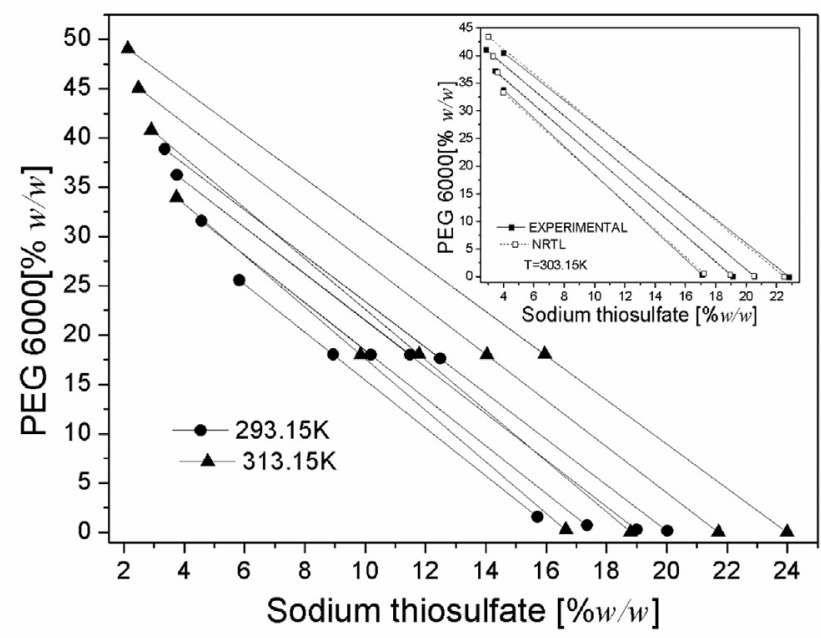

Fig. 5. Liquid-liquid equilibria at different temperatures for the systems composed of PEG 6000 + Sodium Thiosulfate (2) + water (3) ATPSs under atmospheric pressure.

order: $\mathrm{C}_{6} \mathrm{H}_{5} \mathrm{O}_{7}^{-3}>\mathrm{C}_{4} \mathrm{H}_{4} \mathrm{O}_{6}^{-2}>\mathrm{C}_{4} \mathrm{H}_{4} \mathrm{O}_{4}^{-2}$. The position of binodal curves of this study in Fig. 2(a) and (b), when compared with others of the literature, agrees with the values of $\left(\Delta G_{h y d}\right)$ found.

\subsection{Tie line data and correlation}

Compositions of equilibrium phases, length (TLL) and slope $(S)$ of tie lines are given in Table 4. The semi-empirical tests of OthmerTobias [24] and Bancroft [25] agreed well with the tie-line data and presented coefficients of determination ( $R$-square) higher than 0.97 for all systems.

According to the results in Table 3 and in Figs. 3-5, for all ATPSs, with an increase in temperature, the tie lines became more sloped, following the behavior of other PEG-salt systems [46-48]. No remarkable effect of PEG molecular weight was revealed in the tie line slopes. For the sake of clearness, Figs. 3-5 show the calculated tie lines with the NRTL model at $303.15 \mathrm{~K}$ only. Fig. 6 shows higher amounts of salt in initial ternary mixture (global composition) are related to greater $T L L$ values for all PEG-salt systems independently

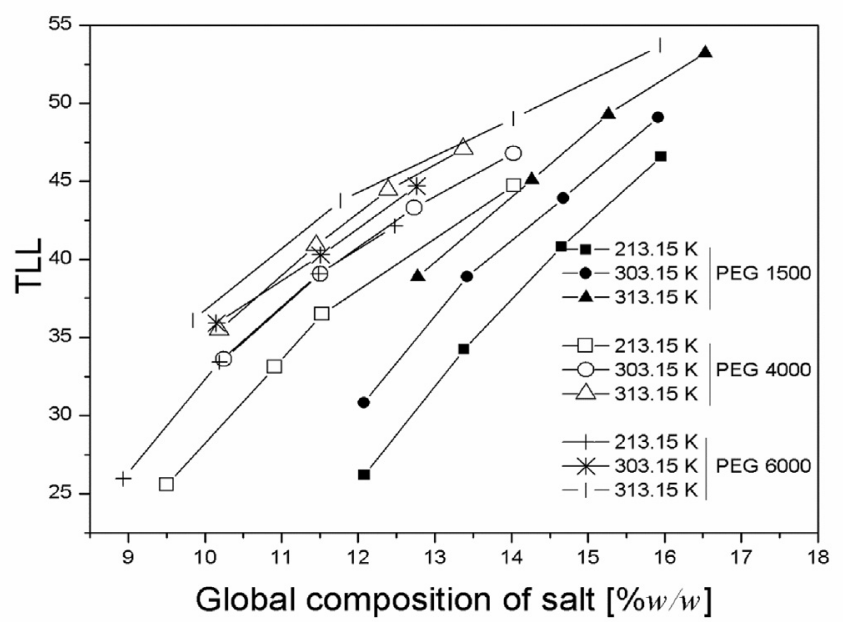

Fig. 6. Tie line length versus global composition of salt for PEG (1) + Sodium Thiosulfate (2) + water (3) ATPSs at different temperatures and under atmospheric pressure. 
Table 5

Binary interaction parameters of the NRTL equation, and correlation performance for the system used in this study.

\begin{tabular}{|c|c|c|c|c|c|c|}
\hline $\mathrm{i} / \mathrm{j}$ & ${ }^{\mathrm{a}} \mathrm{A}_{0 \mathrm{ij}} / \mathrm{K}$ & ${ }^{\mathrm{a}} \mathrm{A}_{0 \mathrm{ji}} / \mathrm{K}$ & ${ }^{\mathrm{a}} \mathrm{A}_{1 \mathrm{ij}}$ & ${ }^{\mathrm{a}} \mathrm{A}_{1 \mathrm{ji}}$ & ${ }^{\mathrm{a}} \alpha_{\mathrm{ij}}$ & ${ }^{\mathrm{a}} \mathrm{rmsd}(\%)$ \\
\hline PEG $1500-\mathrm{Na}_{2} \mathrm{~S}_{2} \mathrm{O}_{3}$ & -688.4 & 4699.7 & 130.380 & -33.450 & 0.2002 & 1.78 \\
\hline PEG 1500-water & -3588.9 & 6709.0 & 68.071 & 0.2676 & 0.4700 & \\
\hline $\mathrm{Na}_{2} \mathrm{~S}_{2} \mathrm{O}_{3}$-water & -117.0 & 784.61 & 66.574 & 128.270 & 0.2000 & \\
\hline PEG $4000-\mathrm{Na}_{2} \mathrm{~S}_{2} \mathrm{O}_{3}$ & -6730.9 & 5360.4 & -34.810 & 24.468 & 0.4700 & 0.93 \\
\hline PEG 4000-water & -3275.4 & 5617.0 & -17.979 & -0.6747 & 0.2337 & \\
\hline $\mathrm{Na}_{2} \mathrm{~S}_{2} \mathrm{O}_{3}$-water & -144.7 & 504.9 & -31.935 & 27.961 & 0.4695 & \\
\hline PEG $6000-\mathrm{Na}_{2} \mathrm{~S}_{2} \mathrm{O}_{3}$ & 2761.2 & 7140.6 & -237.000 & -0.4501 & 0.2000 & 0.96 \\
\hline PEG 6000-water & -2866.3 & 5243.2 & -16.870 & -0.3119 & 0.3075 & \\
\hline $\mathrm{Na}_{2} \mathrm{~S}_{2} \mathrm{O}_{3}$-water & -274.55 & -785.9 & -31.318 & -16.466 & 0.4514 & \\
\hline
\end{tabular}

${ }^{\mathrm{a}}$ In which RMSD is $\delta_{x}=100$. $\left(\left(\sum_{i}^{M} \sum_{j}^{N}\left(x_{i j}^{I . e x p}-x_{i j}^{I . \text { calc }}\right)^{2}+\left(x_{i j}^{I I . e x p}-x_{i j}^{I I . c a l c}\right)^{2}\right) / 2 M N\right)^{1 / 2}, A_{0 i j}$ and $A_{1 i j}$ are the characteristic parameters of energy of the i-j interactions, and parameter $\alpha_{i j}$ is related to the non-randomness of the mixture.

of temperature. On the other hand, TLL increases with the increase in temperature, and this effect is less evident for PEG 6000.

\subsection{NRTL model}

Experimental data were correlated with the non-random twoliquid (NRTL) model on the molar basis [49]. The liquid-liquid equilibrium correlation was made using the estimated molecular energy interaction parameters. The values of the binary interaction parameters obtained for the NRTL model are listed in Table 5 along with the root mean square deviations (RMSD).

As shown in Table 1, the NRTL model was able to represent the phase split over the entire range of compositions analyzed. The mean deviations were found to be $<1,8 \%$. The estimation of the model parameters followed the method described by Stragevitch and d'Ávila [50]. Graphical comparisons between the experimental and calculated data, for all temperatures, are depicted in Figures S1S3 in the Supplementary Material.

\section{Conclusion}

Liquid-liquid equilibrium data of biphasic aqueous systems formed by PEG and sodium thiosulfate pentahydrate at $T=(293.15$, 303.15 and 313.15) $\mathrm{K}$ with $u(T)=0.05$ and under atmospheric pressure were obtained experimentally. Tie line data were verified through equations of Othmer-Tobias and Bancroft indicating the quality of experimental data for both tests. The NRTL model correlated satisfactorily with the experimental data. The effect of the temperature and molecular weight of PEG on the binodal curves were also studied, being demonstrated that biphasic region expands with their increase. On the other hand, temperature affected the slope of the tie lines, but no notable effect was shown for molecular weight of PEG. A comparison between the binodal data of this study and of the literature showed the following order of the salting-out ability for the anions of the salts: $\mathrm{C}_{6} \mathrm{H}_{5} \mathrm{O}_{7}^{-3}$ (citrate) $>\mathrm{S}_{2} \mathrm{O}_{3}^{-2}$ (thiosulfate) $>\mathrm{C}_{4} \mathrm{H}_{4} \mathrm{O}_{6}^{-2}$ (tartrate) $>\mathrm{KC}_{4} \mathrm{H}_{4} \mathrm{O}_{6}^{-2}$ (Ktartrate) $>\mathrm{C}_{4} \mathrm{H}_{4} \mathrm{O}_{4}^{-2}$ (succinate $>\mathrm{CHO}^{-2}$ (formate). This comparison agrees with the values of $\left(\Delta G_{h y d}\right)$. It was also verified that an increase in the amounts of salt in the global composition is related to greater TLL values for all PEG-salt systems.

\section{Acknowledgment}

The authors acknowledge the Brazilian funding agencies $\mathrm{CNPq}$ (302146/2016-4 and 310272/2017-3), FAEPEX/UNICAMP, CAPES for the financial support and scholarships and Espaço da Escrita-PróReitoria de Pesquisa-UNICAMP- for the language services provided. This paper is dedicated to the memory of Prof. Martín Aznar.

\section{Appendix A. Supplementary data}

Supplementary data related to this article can be found at https://doi.org/10.1016/j.fluid.2018.07.035.

\section{References}

[1] Z. Zhao, Q. Li, X. Ji, R. Dimova, R. Lipowsky, Y. Liu, Molar mass fractionation in aqueous two-phase polymer solutions of dextran and poly (ethylene glycol), J. Chromatogr. A 1452 (2016) 107-115.

[2] J.V.D. Molino, V. Marques, D. de Araújo, A.P. Júnior, P.G. Mazzola, M.S.V. Gatti, Different types of aqueous two-phase systems for biomolecule and bioparticle extraction and purification, Biotechnol. Prog. 29 (2013) 1343-1353.

[3] L.H.M. Silva, J.S.R. Coimbra, J.A. Meirelles, Equilibrium phase behavior of poly (ethylene glycol) + potassium phosphate + water two-phase systems at various pH and temperatures, J. Chem. Eng. Data 42 (1997) 389-401.

[4] J.P. Martins, C.P. Carvalho, L.H.M. da Silva, J.S.R. Coimbra, M.C.H. da Silva G.D. Rodrigues, L.A. Minim, Liquid-liquid equilibria of an aqueous two-phase system containing poly(ethylene) glycol 1500 and sulfate salts at different temperatures, J. Chem. Eng. Data 53 (2008) 238-241.

[5] K.E. Gutowski, G.A. Broker, H.D. Willauer, J.G. Huddleston, R.P. Swatloski, J.D. Holbrey, R.D. Rogers, Controlling the aqueous miscibility of ionic liquids: aqueous biphasic systems of water-miscible ionic liquids and waterstructuring salts for recycle, metathesis, and separations, J. Am. Chem. Soc 125 (2003) 6632-6633.

[6] R.D. Noble, D.L. Gin, Perspective on ionic liquids and ionic liquid membranes, J. Membr. Sci. 369 (2011) 1-4.

[7] M.W. Beijerinck, Über eine Eigentümlichkeit der löslichen Stärke. Zentralblatt for Bakteriologie, Parasiten und Infektionskrankheiten 2 (1896) 679-699.

[8] L.H.M. da Silva, W. Loh, Calorimetric investigation of the formation of aqueous two-phase systems in ternary mixtures of water, poly (ethylene oxide) and electrolytes (or dextran), J. Phys. Chem. B 104 (2000) 10069-10073.

[9] C.P. Carvalho, J.S.R. Coimbra, I.A.F. Costa, L.A. Minin, M.C. Maffia, Influence of the temperature and type of salt on the phase equilibrium of PEG $1500+$ Potassium phosphate and PEG 1500 + sodium citrate aqueous two-phase systems, Quim. Nova 31 (2008) 209-213.

[10] S.C. Silvério, J. Gracia, J.A. Teixeira, E.A. Macedo, Polyethylene glycol 8000+ citrato salts aqueous two-phase systems: relative hydrophobicity of the equilibrium phases, Fluid Phase Equil. 407 (2016) 296-303.

[11] P.A. Albertsson, Partition of proteins in liquid polymer-polymer two-phase systems, Nature 182 (1958) 709-711.

[12] P.A. Albertsson, Partition of Cell and Macromolecules, John Wiley, New York, 1986.

[13] Yu-liang Li, Meng-shi Zhang, Hang Su, Qian Liu, Wei-sheng Guan, Liquidliquid equilibria of a aqueous two phases systems of the ionic liquid brominated n-ethyl pyridine and sodium dihydrogen phosphate. sodium sulphate. amonium citrate and potassium tartrate at different temperatures: experimental determination and correlation, Fluid Phase Equil. 341 (2013) 70-77.

[14] J. Han, C. Yu, Y. Wang, X. Xie, Y. Yan, G. Yin, W. Guan, Liquid-Liquid equilibria of ionic liquid 1-butyl-3methylimidazolium tetrafluoroborate and sodium citrate/tartarate/acetate aqueous two-phase systems at 298.15K: experiment and correlation, Fluid Phase Equil. 295 (2010) 98-103.

[15] J. Han, Y. Wang, C. Yu, C. Li, Y. Yan, Y. Liu, L. Wang, Separation, concentration and determination of chloramphenicol in environment and food using an ionic liquid/salt aqueous two-phase flotation system coupled with highperformance liquid chromatography, Anal. Chim. Acta 685 (2011) 138-145.

[16] B. Perez, L.P. Malpiedi, G. Tubío, B. Nerli, P.A. Pessôa Filho, Experimental determination and thermodynamic modeling of phase equilibrium and protein partitioning in aqueous two-phase systems containing biodegradable salts, J. Chem. Thermodyn. 56 (2013) 136-143.

[17] A. Salabat, The influence of salts on the phase composition in aqueous twophase systems: experiments and predictions, Fluid Phase Equil. 489 (2001) 187-188. 
[18] L.A. Ferreira, P. Parpot, J.A. Teixeira, L.M. Mikheeva, B.Y. Zaslavsky, Effect of $\mathrm{NaCl}$ additive on properties of aqueous PEG-sodium sulfate two-phase system, J. Chromatogr. a. 12220 (2012) 14-20.

[19] K.P. Ananthapadmanabhan, E.D. Goddard, Aqueous biphase formation in polyethylene oxide-inorganic salt systems, Langmuir 3 (1987) 25-31.

[20] S.M. Snyder, K.D. Cole, D.C. Szlag, Phase compositions, viscosities and densities for aqueous two-phase systems composed of polyethylene Glycol and various salts at 25.degree.C, J. Chem. Eng. Data 37 (1992) 268-274.

[21] L.A. Ferrreira, J.A. Teixeira, Salt effect on the (polyethylene glycol $8000+$ sodium sulfate) aqueous two-phase system: relative hydrophobicity of the equilibrium phases, J. Chem. Thermodyn. 43 (2011) 1299-1304.

[22] L.A. Ferrreira, J.A. Teixeira, Salt effect on the aqueous two-phase system PEG 8000 - sodium sulfate, J. Chem. Eng. Data 56 (2011) 133-137.

[23] I.J.B. Santos, R.M.M. Carvalho, M.C.H. da Silva, L.H.M. da Silva, Phase diagram, densities, and the refractive index of new aqueous two-phase system formed by PEO1500 + thiosulfate + H2O at different temperatures, J. Chem. Eng. Data 57 (2012) 274-279.

[24] D.F. Othmer, P.E. Tobias, Tie-line correlation, Ind. Eng. Chem. 34 (1942) 693-696.

[25] P. González-Tello, F. Camacho, G. Blázquez, Liquid-liquid equilibrium in the system poly (ethylene glycol) + MgSO4 + H2O at 298 K, J. Chem. Eng. Data 41 (1996) 1333-1336.

[26] J.C. Merchuk, B.A. Andrews, J.A. Ansejo, Aqueos two-phase systems for protein separation: studies on phase inversion, J. Chromatogr. B 711 (1998) 285-293.

[27] P.O.B. Homrich, L.R.B. Mariutti, N. Bragagnolo, R. Ceriani, Solubility behavior of mixtures containing refined soybean oil and low-toxic solvents at different temperatures, Fluid Phase Equil. 442 (2017) 87-95.

[28] S.P. Amaresh, M. Shreela, I. Regupathi, T. Murugesan, Liquid- liquid equilibrium of poly (ethylene glycol) $4000+$ diAmmonium hydrogen phosphate + water at different temperatures, J. Chem. Eng Data 53 (2008) 1574-1578.

[29] I. Regupathi, M. Shreela, R. Govindarajan, S.P. Amaresh, T. Murugesan, Liquidliquid equilibrium of poly (ethylene glycol) $6000+$ triammonium citrate + water systems at different temperatures, J. Chem. Eng. Data 54 (2009) 1094-1097.

[30] P. Martins, F.C. De Oliveira, J.S.R. Coimbra, L.H.M. Da Silva, M.C.H. Da silva, I.S.B. do Nascimento, Equilibruim phase behavior for ternary mixtures of poly(ethylene) glycol $6000+$ water + sulfate salts at different temperatures, J. Chem. Eng. Data 53 (2008) 2441-2443.

[31] M.T. Zafarani-Moattar, S. Hamzehzadeh, S. Hossinzadeh, Phase diagrams for liquid-liquid equilibrium of ternary poly(ethylene glycol) + di-sodium tartrate aqueous system and vapor-liquid equilibrium of constituting binary aqueous systems at $\mathrm{T}=(298.15 .308 .15$. and 318.15$) \mathrm{K}$ : experiment and correlation, Fluid Phase Equil. 268 (2008) 142-152.

[32] M.T. Zafarani-Moattar, R. Sadeghi, Liquid-liquid equilibria of aqueous twophase systems containing polyethyleneglycol and sodium dihydrogen phosphate or disodium hydrogen phosphate. Experiment and correlation, Fluid Phase Equil. 181 (2001) 95-112.

[33] T.A. Graber, M.E.T. Taboada, J.A. Asenjo, B.A. Andrews, A influence of molecula weight of the polymer on the liquid-liquid equilibrium of the 59 poly (ethylene glycol $+\mathrm{NaNO}+\mathrm{H} 2 \mathrm{O}$ system at 298.15K, J. Chem. Eng. Data 46 (2001) 765-768.

[34] W. Zhang, y. Hu, J. Han, L. Ni, Y. Wu, Liquid-liquid equilibrium of aqueous twophase systems containing poly (ethylene glycol) de different molecular weights and several ammonium salts at 298.15K, Thermochim. Acta 560 (2013) 47-54.

[35] G.F. Murari, J.A. Penido, P.A.L. Machado, L.R. De Lemos, N.H.T. Lemes,
L.S. Virtuoso, G.D. Rodrigues, A.B. Mageste, Phase diagrams of aqueous twophase systems formed by polyethylene glycol + ammonium sulfate + water: equilibrium data and thermodynamic modeling, Fluid Phase Equil. 406 (2015) 61-69.

[36] L. Yan-Min, Y. Yan-Zhao, Z. Xi-Dan, X. Chuan-Bo, Bovine serum albumin partitioning en polyethylene glycol (PEG/potassium citrate aqueous twophase systems, Food Bioprod. Process. 88 (2010) 40-46.

[37] M.T. Zafarani-Moattar, R. Sadeghi, A. Hamidi, A. Liquid-liquid equilibria of an aqueous two-phase system containing polyethylene glycol and sodium citrate: experiment and correlation, Fluid Phase Equil. 219 (2004) 149-155.

[38] K. Wysoczanska, E. Macedo, A. Effect of molecular weight of polyethylene glycol on the partitioning of DNP-amino acids: PEG $(4000,6000)$ with sodium citrate at 298.15K, Fluid Phase equilib 428 (2016) 84-91.

[39] M.T. Zafarani-Moattar, S. Hamzehzadeh, Liquid-liquid equilibria of aqueous two-phase systems containing polyethylene glycol and sodium succinate or sodium formate, Chalphad 29 (2005) 1-6.

[40] M.T. Zafarani-Moattar, S. Hamzehzadeh, S. Hosseinzadeh, Phase diagrams for liquid-liquid equilibrium of ternary poly(ethylene glycol) + di-sodium tartrate aqueous system and vapor-liquid equilibrium of constituting binary aqueous systems at $\mathrm{T}=(298.15$. 308.15. and 318.15) $\mathrm{K}$ Experiment and correlation, Fluid Phase Equil. 268 (2008) 142-152.

[41] M.T. Zafarani-Moattar, S. Tolouei, liquid-liquid equilibria of aqueous twophase systems containing polyethylene glycol 4000 and di-potassium tartrate. potassium sodium tartrate. or di-potassium oxalate: experiment and correlation, CHALPHAD 32 (2008) 655-660.

[42] V. Marcus, Thermodynamics of solvation of ions. Part 5. Gibbs free energy of hydration at 298.15 k, J. Chem. Soc., Faraday Trans. 87 (1991) 2995-2999.

[43] M.T. Zafarani-Moattar, S. Hamzehzadeh, Effect of pH on the phase separation in the ternary aqueous system containing the hydrophilic ionic liquid 1-butyl3 methylimidazolium bromide and the kosmotropic salt potassium citrate at $\mathrm{T}=298.15$, Fluid Phase Equil. 304 (2011) 110-120.

[44] E. Nemati-kande, H. Shekaari, Salting-out effect of sodium, Potassium, Carbonate, Sulfite, Tartrate and thiosulfate íns on aqueous mixtures of acetonitrile or 1-methyl-2-pyrrolidone: a liquid-liquid equilibrium study, Fluid Phase Equil. 360 (2013) 357-366.

[45] Y. Li, L. Yang, X. Zhao, W. Guan, Liquid-Liquid equilibria of ionic liquid Nethylpyridinium tetrafluoroborate + trisodium citrate/ammonin citrate tribasic/sodium succinate/sodium tartrate aqueous two-phase systems at 298.15 K, Thermochim. Acta 550 (2012) 5-12.

[46] M.T. Zafarani-moattar, J. Gasemi, Liquid-liquid equilibrium of aqueous twophase systems containing poly(ethylene glycol) and ammonium dihydrogen phosphate or diammonium hydrogen phosphate: experiment and correlation, Fluid Phase Equil. 198 (2002) 281-291.

[47] N. Voros, P. Proust, A. Fredenslund, Liquid-liquid equilibria of aqueous twophase systems containing salts and polyethylene glycol, Fluid Phase Equil. 90 (1993) 333-353.

[48] R.M. Oliveira, J.S.R. Coimbra, L.A. Minim, L.H.M. da Silva, M.P.F. Fontes, Liquid-liquid equilibria of biphasic systems composed of sodium citrate + polyethylene(glycol) 1500 or 4000 at different temperatures, J. Chem. Eng. Data 53 (2008) 895-899.

[49] H. Renon, J.M. Prausnitz, Local compositions in thermodynamic excess functions for liquid mixtures, AIChE J. 14 (1968) 135-144.

[50] L. Stragevitch, S.G. D'ávila, Application of a generalized maximum likelihood method in the reduction of multicomponent liquid-liquid equilibrium data, Braz. J. Chem. Eng. 6 (1997) 252-263. 